TECHNO

Vol.21, No.2, Oktober 2020, Hal. 99-110

P-ISSN: 1410-8607, E-ISSN: 2579-9096

\title{
VIDEO CONFERENCE PADA OPENSTACK MENGGUNAKAN OPENMEETING SEBAGAI INFRASTRUCTURE AS A SERVICE (IaAS)
}

\author{
Bongga Arifwidodo $^{1}$, Wasis Rezki Baskoro ${ }^{2}$, Jafaruddin Gusti Amri Ginting ${ }^{3}$ \\ Program Studi S1 Teknik Telekomunikasi, Institut Teknologi Telkom Purwokerto \\ Institut Teknologi Telkom Purwokerto
}

Informasi Makalah

Dikirim, 01 September 2020

Direvisi, 21 September 2020

Diterima, 30 September 2020

\section{Kata Kunci:}

Openstack

Cloud

Qos

server

\section{INTISARI}

Era Pandemi menyebabkan peningkatan penggunaan aplikasi konferensi video yang tiba-tiba dan siginifikan. Bagi perusahaan harus segera beradaptasi dalam hal aplikasi komunikasi. Salah satu aplikasi yang bisa digunakan yaitu openmeetings. Openmeetings adalah aplikasi yang digunakan sebagai pengatur konferensi yang terinstal pada server. Umumnya server dibangun menggunakan komponen fisik, namun memiliki keterbatasan sehingga seringkali mengalami penurunan performa dalam segi kecepatan server dalam menjalankan layanan. Salah satu upaya meningkatkan performa server harus menambah atau mengganti perangkat keras sehingga kurang menguntungkan pada biaya operasional. Konsep Cloud selain efisien dari segi biaya operasi server, juga handal dari segi ketersediaan layanan. Sistem Cloud merupakan sebuah model Client-server, dapat diakses oleh pengguna dimana saja dan kapan saja. Membangun Cloud salah satunya dapat menggunakan software open source, yakni Openstack. Penelitian melakukan perbandingan antara harga komponen cloud dengan komponen fisik, kemudian melakukan pengujian Video Conference yang di jalankan dalam Openstack untuk mengetahui kinerja dari sisi Quality of Service (QoS) meliputi delay, packetloss, jitter dan throughput. Hasilnya disimpulkan menggunakan cloud lebih efisien dibandingkan dengan menggunakan server fisik. Nilai rata-rata terbesar pada sisi client, dengan throughput sebesar $639.85 \mathrm{kbps}$, delay sebesar $30.22 \mathrm{~ms}$, jitter sebesar 10.35 ms dan packetloss sebesar $0.94 \%$, untuk nilai rata-rata terbesar pada sisi server, dengan throughput sebesar 1,856.55 kbps, delay sebesar $10.19 \mathrm{~ms}$, jitter sebesar $6.18 \mathrm{~ms}$ dan packetloss sebesar $0.87 \%$.

\section{Keyword: \\ Openstack \\ Cloud \\ Qos \\ server}

\begin{abstract}
The Pandemic era led to a sudden and significant growth in the role of video conferencing applications. Companies must immediately adapt in terms of communication applications. One application that can be used is an open meeting. It is a conference manager application that is installed on the server. Generally, servers are built using physical components, but they have limitations so that they often experience a decrease in performance in terms of server speed in running services. One of the efforts to improve server performance is to add or replace the hardware to be less profitable in operational costs. Besides being efficient in terms of server operating costs, the Cloud concept is also reliable in service availability. Cloud is a clientserver model, accessible to users anywhere and anytime. One of the ways to build a cloud can use open source software, namely an open stack. The study conducted a comparison between the price of cloud components and physical components, then tested the Video Conference, which was run in Open stack to determine the performance in terms of Quality of Service (QoS), including delay, packet loss, jitter, and throughput. The results concluded that using the cloud is more efficient than using a physical server. The most considerable average value is on the client-side, with a throughput of $639.85 \mathrm{~KB} / \mathrm{s}$, a delay of $30.22 \mathrm{~m} / \mathrm{s}$, a jitter of $10.35 \mathrm{~m} / \mathrm{s}$, and a packet loss of $0.94 \%$. For the most considerable average value of the server-side, with a throughput of 1.856 .55 kbps, a delay of $10.19 \mathrm{~ms}$, jitter of $6.18 \mathrm{~ms}$, and a packet loss of $0.87 \%$.
\end{abstract}




\section{Korespondensi Penulis:}

Bongga Arifwidodo

Program Studi S1 Teknik Telekomunikasi

Institut Teknologi Telkom Purwokerto

Email: bongga@ittelkom-pwt.ac.id

\section{PENDAHULUAN}

Era Pandemi menyebabkan peningkatan penggunaan aplikasi konferensi video yang tiba-tiba dan signifikan [1]. Komunikasi adalah suatu bagian yang tidak dapat dipisahkan dalam kehidupan dan menurut hasil survey dari Asosiasi Penyelenggara Jasa Internet Indonesia (APJII) menyatakan bahwa penggunaan telekomunikasi terutama penggunaan internet semakin hari semakin berkembang pesat pada 2017 mencapai 171,17 juta pengguna [2], bentuk dan media untuk berkomunikasi juga mengalami perubahan.

Seiring tantangan yang ada, sebuah perusahaan dan instansi seringkali menyelenggarakan rapat atau pertemuan. Tantangannya adalah keterbatasan yaitu tempat dan waktu yang berbeda-beda tiap orang. Solusi menggunakan teknologi video conference sehingga jarak dan waktu tidak menjadikan kendala saat akan diadakan suatu rapat. Salah satu aplikasi untuk menjalankan video conference adalah openmeetings. Open meetings yaitu sistem secara virtual di mana masing-masing anggota rapat tidak harus bertatap muka dalam suatu ruangan rapat tetapi dapat digantikan dengan teknologi streaming berbasis web dengan memanfaatkan jaringan internet/intranet. Agar aplikasi open meetings tersebut dapat berjalan, maka dibutuhkan suatu perancangan server sebagai penghubung jaringan [3].

Kondisi tersebut membuat teknologi segera beradaptasi agar kebutuhan komunikasi berjalan maksimal. Komputasi awan menawarkan akses sesuai permintaan sumber daya komputasi, infrastruktur dan data dioperasikan dari sumber jarak jauh. Teknologi baru ini telah membuka cara baru sumber daya yang fleksibel ketentuan untuk bisnis untuk mengelola aplikasi IT dan data menanggapi tuntutan baru dari pelanggan [4]. Konsep Cloud adalah mengubah hardware-dedicated menjadi software-dedicated sehingga Cloud menjadi salah satu solusi yang lebih praktis dan dengan biaya minimal [5], karena jika terjadi penurunan performa tidak perlu menambah komponen secara fisik melainkan menambah secara logic. Untuk membangun Cloud itu sendiri menggunakan software openstack. Openstack merupakan software open source untuk membangun cloud computing hingga sekarang platform ini telah membentuk ekosistem yang kuat dengan fungsional modul yang melimpah [6]. Kehandalan Openstack layanan IaaS sangat baik sekali, dimana metode pemulihannya yang cepat dan handal saat server fisik maupun VM- virtual machine dalam keadaan tidak berfungsi atau mati [7].

Penelitian Hafis Nurdin, Sumarna dan Felix Wuryu Handono yaitu Pengimplementasian Cluster Openmeetings guna meningkatkan efektivitas belajar mengajar jarak jauh. Hasilnya menunjukan bahwa setiap pengajar dengan siswanya dan materi pengajaran yang sama akan menempati room yang sama walaupun server nya berbeda, hal ini meunjukan pembagian beban ke setiap server tidak hanya bertumpu pada satu buah server saja, akan tetapi terbagi kesemua server yang ada, sehingga kinerja dari tiap server menjadi ringan [11].

Penelitian Ananth M.D. dan Rinki Sharma [10] pada tahun 2017. Menganalisis biaya dan performasi penggunaan NFV berbasis cloud. Software cloud yang digunakan adalah openstack dengan memvirtualkan layanan web server. Pada penelitian ini, hasil yang didapatkan dari performansi CPU dengan 4 pengguna yang mengakses layanan sebesar $0.3 \%$ pada cloud system dan $0.31 \%$ pada physical system, dengan 40 pengguna yang mengakses layanan sebesar $0.3 \%$ pada cloud system dan $0.31 \%$ pada physical system, dengan 400 pengguna yang mengakses layanan sebesar $0.5 \%$ pada cloud system dan $1.04 \%$ pada physical system, untuk 2000 pengguna yang mengakses layanan sebesar $1.11 \%$ pada cloud system dan $1.43 \%$ pada physical system, dan untuk 4000 yang mengakses layanan sebesar $0.65 \%$ pada cloud system dan $0.97 \%$ pada physical system. Berdasarkan parameter tersebut sistem cloud layak untuk diimplementasikan.

Dalam penelitian ini akan di implementasikan Video conference pada Cloud dengan software Video conference yang digunakan adalah Openmeetings dan software pembangun infrastruktur Cloud-nya adalah Openstack. Beban kerja yang berjalan pada contoh platform OpenStack adalah paling stabil saat 
membandingkan dengan instance cloud lainnya-vogel [8]. Layanan pada Video conference yang akan dilakukan uji coba adalah dengan melakukan suatu video conference dengan jumlah client yang bervariasi yaitu 3 client, 5 client, 7 client dan 9 client-fauzan [9]. Kemudian akan dilakukan pengukuran kinerja parameter QoS.

\section{METODE PENELITIAN}

\subsection{Alur Penelitian}

Penelitian dilakukan dengan cara membuat sistem yang dapat digunakan untuk video conference yang terinstall di dalam Openstack. Kemudian mengumpulkan data dan menganalisa. Hasil analisis tersebut digunakan untuk mengambil suatu kesimpulan. Secara garis besar ditunjukkan pada Gambar 1.:

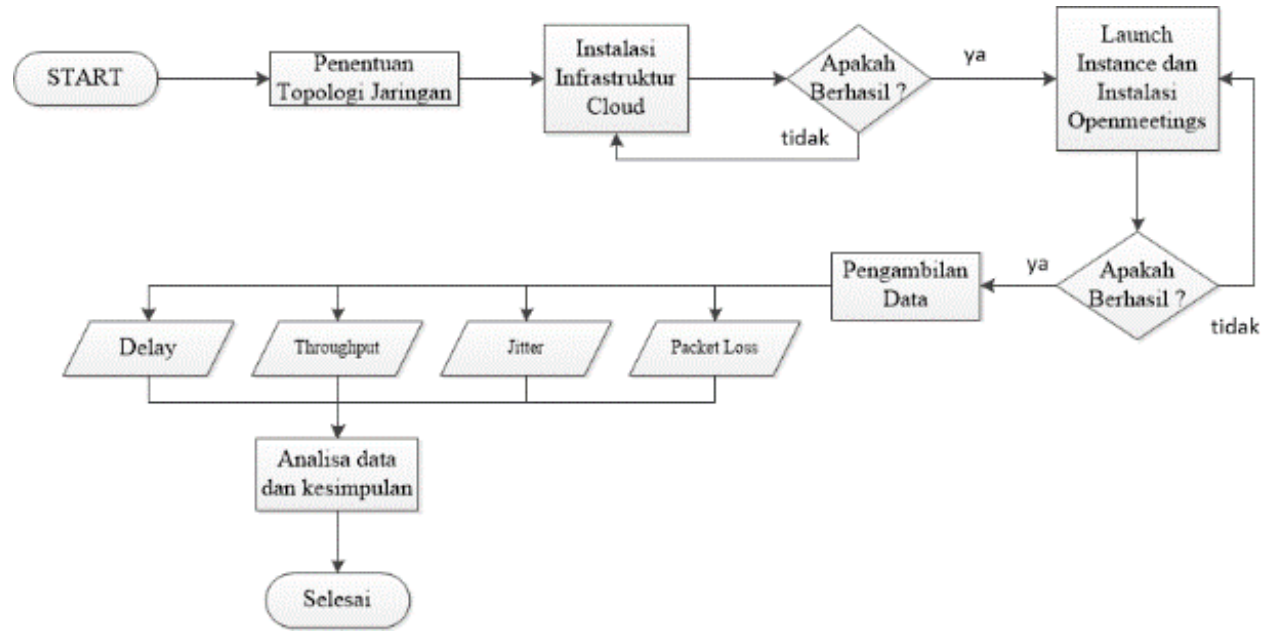

Gambar 1. Alur Penelitian

\subsection{Topologi dan Instalasi Infrastuktur Cloud}

Langkah awal dari penelitian ini adalah dengan membuat topologi, setelah itu membangun infrastruktur Cloud dengan menggunakan Openstack yang dibangun pada sistem operasi CentOS 7. Topologi jaringan fisik ditunjukan pada Gambar 2:

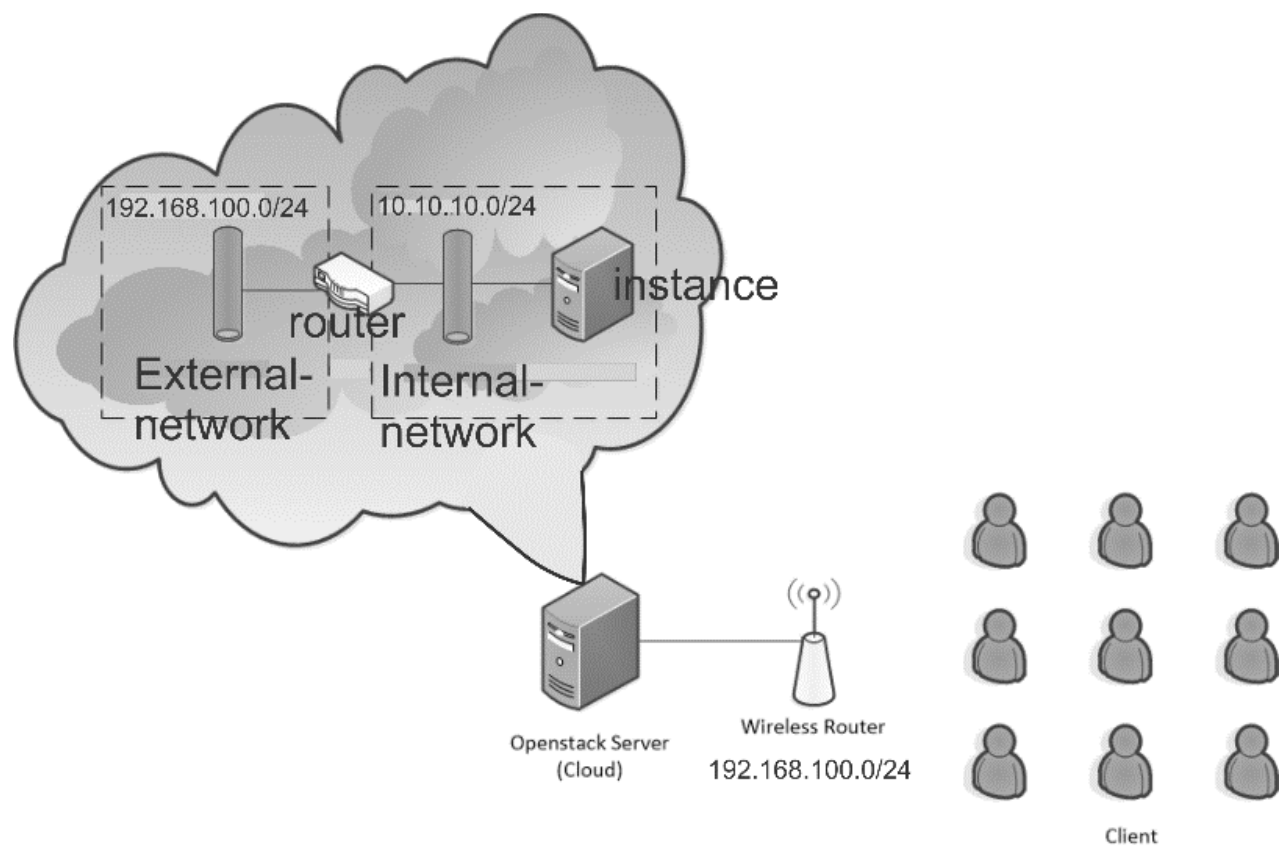

Gambar 2. Topologi Jaringan Fisik 
Saat membangun infrastruktur cloud, kami menggunakan software openstack yang berjalan pada sistem operasi CentOS 7 dan layanan video conference menggunakan software openmeetings dan dibuat secara virtual di dalam instance.

\subsection{Pengambilan Data} Tabel 1.

Data didapat dengan cara menguji layanan video conference dengan menggunakan skenario pada

Tabel 1. Jumlah client

\begin{tabular}{cl}
\hline Layanan & Variabel \\
\hline & 3 Client \\
& 5 Client \\
Video conference & 7 Client \\
& 9 Client
\end{tabular}

Parameter QoS [12] dalam pengujian ini, yakni delay, jitter, throughput, packet loss di sisi upload dan download pada protokol RTMP (Real Time Messaging Protocol) serta menggunakan jumlah client yang bervariasi.

\section{a. Throughput}

Throughtput adalah nilai rata - rata pengsiriman yang sukses melalui saluran telekomunikasi dalam suatu pengiriman. Throughtput diukur dalam satuan bit per second (bps atau bit/s). Rumus menghitung throughtput ditunjukkan pada persamaan 1 .

$$
\text { Throughtput }(\text { bps })=\frac{\text { Packet Data yang diterima }(\text { bit })}{\text { Waktu Pengiriman Packet }(\text { second })}
$$

\section{b. Delay}

merupakan waktu yang diperlukan sebuah paket untuk melakukan perjalanan dari pengiriman ke penerima. Rumus menghitung delay ditunjukkan pada persamaan 2.

$$
\text { Delay Rata }- \text { Rata }=\frac{\text { Total Delay }}{\text { Total Paket yang diterima }}
$$

Klasifikasi standarisasi delay berdasarkan TIPHON ditunjukkan pada Tabel 2.

Tabel 1 Klasifikasi standarisasi delay

\begin{tabular}{ccc}
\hline No & Kategori & Besar $(\mathrm{ms})$ \\
\hline 1 & Sangat Baik & $<150$ \\
2 & Baik & $151-350$ \\
3 & Cukup Baik & $350-449$ \\
4 & Tidak Direkomendasikan & $>450$ \\
\hline
\end{tabular}

\section{c. Packet loss}

Packet loss merupakan parameter yang menggambarkan kondisi yang menunjukkan jumlah paket yang hilang. Rumus untuk menghitung packet loss ditunjukkan pada persamaan 3 .

$$
\text { Packet Loss }=\frac{(\text { Paket data dikirim-paket data diterima }) \times 100 \%}{\text { paket data yang dikirim }}
$$


Klasifikasi standarisasi packet loss berdasarkan TIPHON ditunjukkan pada Tabel 3.

Tabel 2 Klasifikasi standarisasi Packet loss

\begin{tabular}{ccc}
\hline No & Kategori & Besar $(\%)$ \\
\hline 1 & Sangat Baik & $0-2$ \\
2 & Baik & $3-14$ \\
3 & Cukup Baik & $15-24$ \\
4 & Tidak Direkomendasikan & $>25$
\end{tabular}

\section{d. Jitter}

Jitter merupakan variasi delay yang terjadi akibat Panjang antrian dalam suatu pengelolahan data dan reassemble paket data di akhir pengiriman akibat kegagalan sebelumnya. Rumus menghitung Jitter ditunjukkan pada persamaan 4 .

$$
\text { Jitter }=\frac{\text { Total variasi delay }}{\text { Total Paket yang diterima-1 }}
$$

Klasifikasi standarisasi Jitter berdasarkan TIPHON ditunjukkan pada Tabel 4

Tabel 3 Klasifikas standarisasi jitter

\begin{tabular}{ccc}
\hline No & Kategori & Besar $(\mathrm{ms})$ \\
\hline 1 & Sangat Baik & $0-74$ \\
2 & Baik & $75-124$ \\
3 & Cukup Baik & $124-224$ \\
4 & Tidak Direkomendasikan & $>225$ \\
\hline
\end{tabular}

Setiap client yang terlibat dalam video conference menggunakan resolusi kamera paling besar dalam openmeetings yaitu 1024 x 600 [16:9] serta pengujian ini dilakukan dalam durasi 1 menit dan 5 menit yang bertujuan untuk menguji ketahanan atau performa dari server openmeetings yang dijalankan dalam cloud.

\subsection{Konfigurasi Openstack}

Penelitian ini menggunakan Openstack untuk membangun layanan Cloud Computing. Konfigurasi Openstack yang terinstal adalah Horizon (Dashboard), Swift (Object Storage), Nova (Compute), Glance (Image Service), Cinder (Block Storage), Neutron (Networking). Beberapa tahapan dalam instalasi Openstack menggunakan packstack pada CentOS 7:

a. Disable SELinux

SELinux (Security Enchanced Linux) merupakan peningkatan keamanan dari sistem yang ada di Linux.

\#vi /etc/selinux/config

Edit SELINUX=enforcing menjadi SELINUX=disabled

b. Setup OpenStack Repository

Repository merupakan kumpulan paket aplikasi yang didapatkan dari Server Mirror website paket tersebut.

$$
\begin{aligned}
& \text { \#yum install -y centos-release-openstack-rocky } \\
& \text { \#yum update -y }
\end{aligned}
$$

c. Install Packstack 
Packstack merupakan sebuah kumpulan paket yang berisi komponen dari openstack.

$$
\begin{aligned}
& \text { \#yum install -y openstack-packstack } \\
& \text { \#packstack -allinone -provision-demo=n } \\
& \text { \#reboot }
\end{aligned}
$$

d. Mengkonfigurasi $b r$-ex

Bridge Interface atau $b r$-ex berfungsi untuk menghubungkan dua atau lebih interface.

\#cp /etc/sysconfig/network-script/ifcfg-enp4s0
/etc/sysconfig/networkscript/ifcfg-br-ex
\#vi /etc/sysconfig/network-scripts/ifcfg-br-ex
DEVICE=br-ex
DEVICETYPE=ovs
TYPE=OVSBridge
BOOTPROTO=static
IPADDR=192.168.100.65
PREFIX=24
GATEWAY=192.168.100.1
DNS1=8.8.8.8
DNS2=8.8.4.4
ONBOOT=yes
\# vi /etc/sysconfig/network-scripts/ifcfg-enp4s0
DEVICE=enp4s0
TYPE=OVSPort
ONEVICETYPE=ovs

*sesuaikan ifcfg-enp4s0 dengan hardware yg ada seperti, ifcfg-eth0, ifcfg ens192, dll.

e. Lakukan reboot dan login admin melalui dashboard http://192.168.100.65/, untuk user dan password bisa dicek file keystonerc_admin yang ada didalam folder/root/

f. Membuat Network dan router

Network dan router yang dibuat dalam openstack ini berfungsi untuk menghubungkan virtual network dengan jaringan luar sehingga dapat terhubung dengan client. 


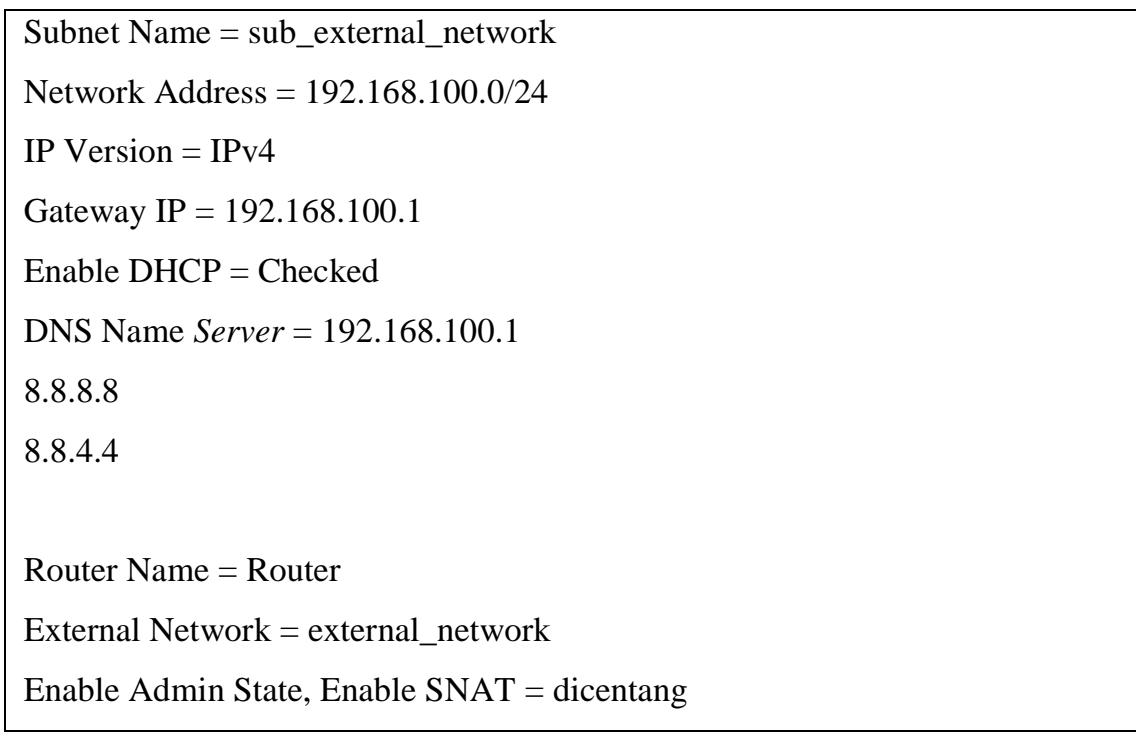

\subsection{Konfigurasi Openmeetings}

Pada penelitian ini menggunakan Openmeetings untuk membanun video conference. Berikut langkah instalasi Openmeetings.

a. Update dan Upgrade sistem operasi Ubuntu.

Update berfungsi untuk memperbarui daftar paket yang tersedia dalam Ubuntu, Upgrade berfungsi untuk menginstal kembali aplikasi yang ada kedalam versi yang terbaru.

$$
\begin{aligned}
& \text { \$ sudo apt-get update } \\
& \text { \$ sudo apt-get upgrade }
\end{aligned}
$$

b. Instal Java, Adobe Flash Player, FFmpeg dan MariaDB

Java Virtual Machine adalah nama sekumpulan teknologi untuk membuat dan menjalankan program java dimana para objek saling berinteraksi satu dengan lainnya [13]. Flash Player merupakan plugin yang berfungsi untuk menampilkan video streaming, memberikan konten web seperti desain, animasi, antarmuka di semua browser [14]. MariaDB adalah sebuah implementasi dari sistem manajemen database, MariaDB adalah satu database server terpopuler [15].

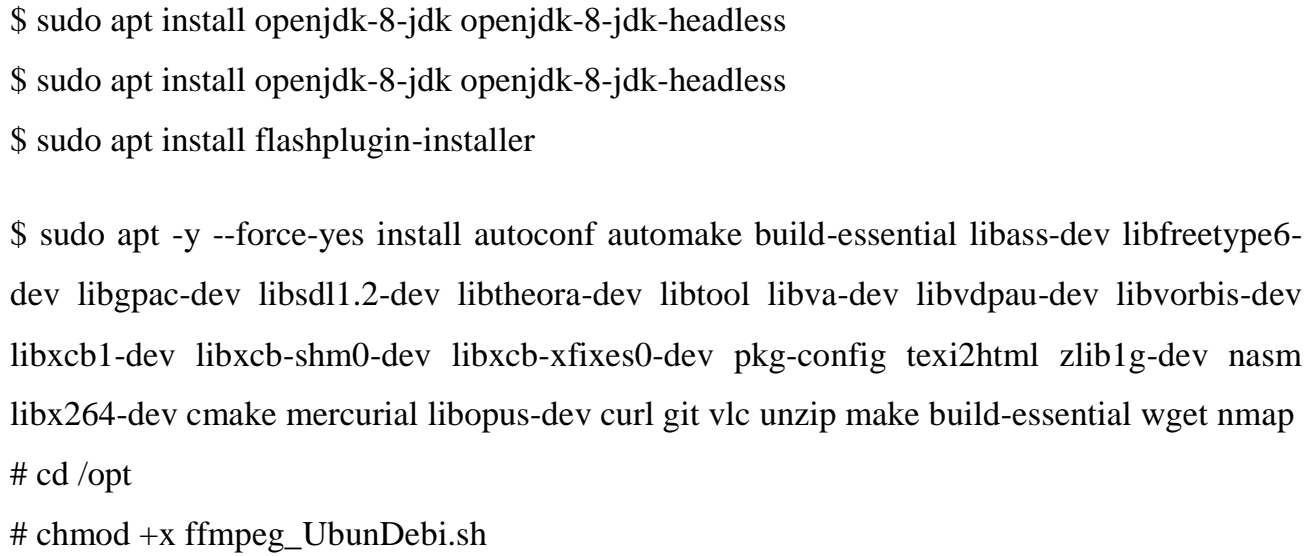




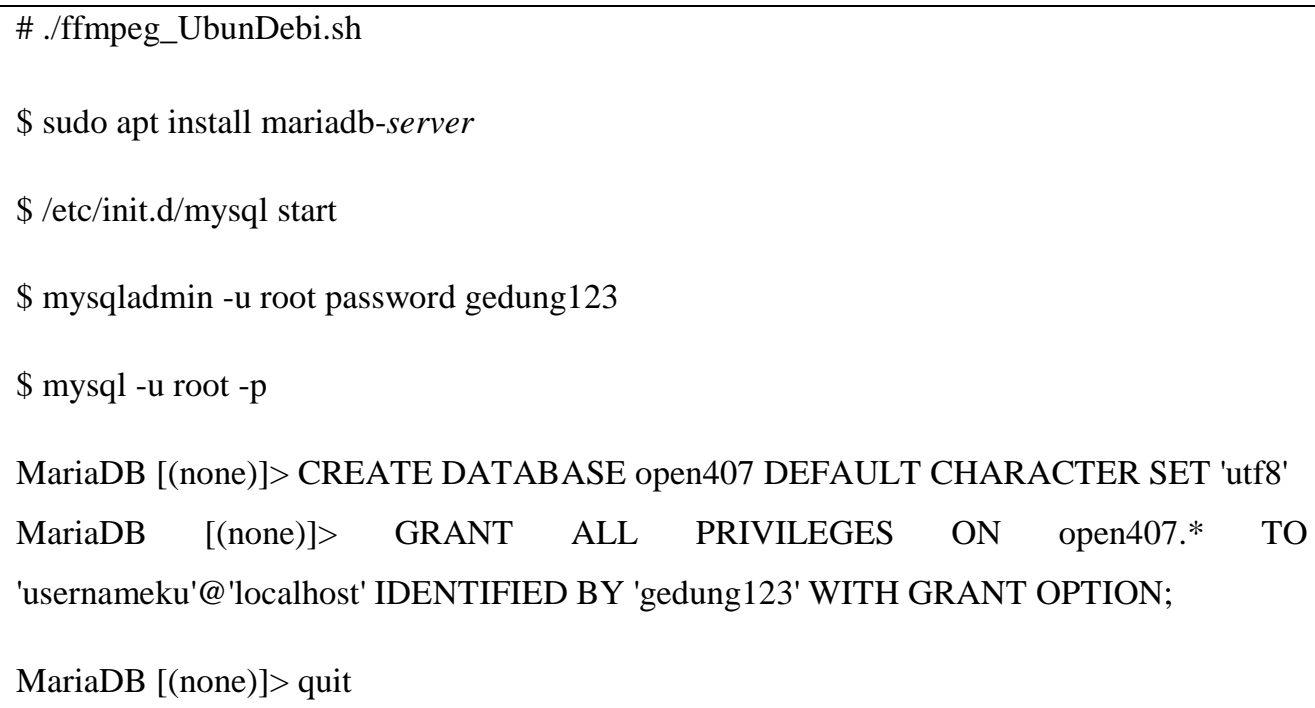

c. Instal Openmeetings dan Install Red5

Red5 merupakan server streaming media perangkat lunak yang di implementasikan dalam java [16].

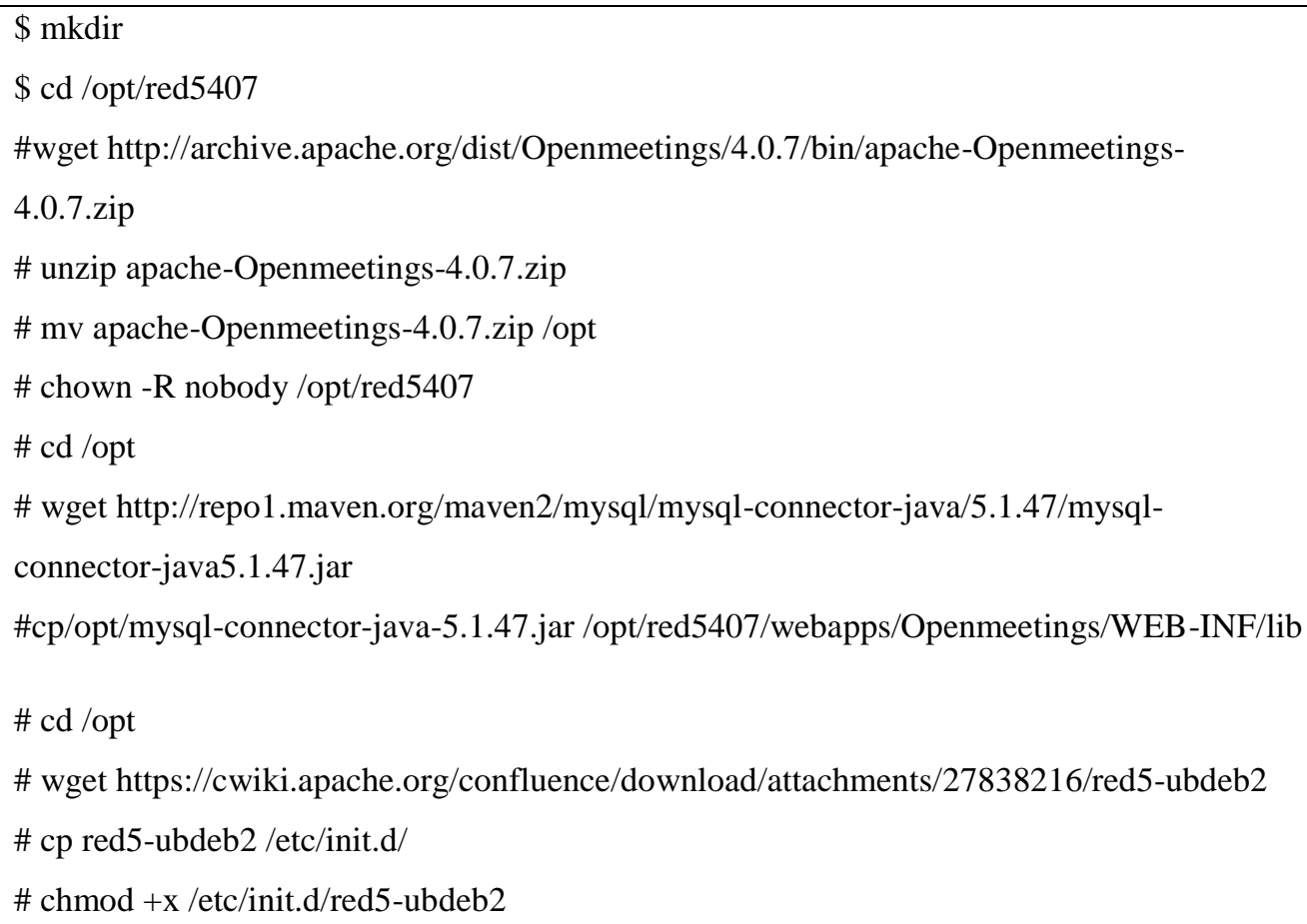

d. Install LibreOffice, Konfigurasi serta install ImageMagick dan Sox sebagai aplikasi pendukung untuk konferensi seperti penggunaan file office ataupun file gambar dalam konferensi.

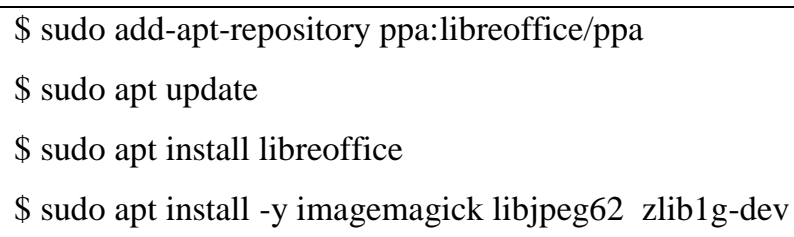




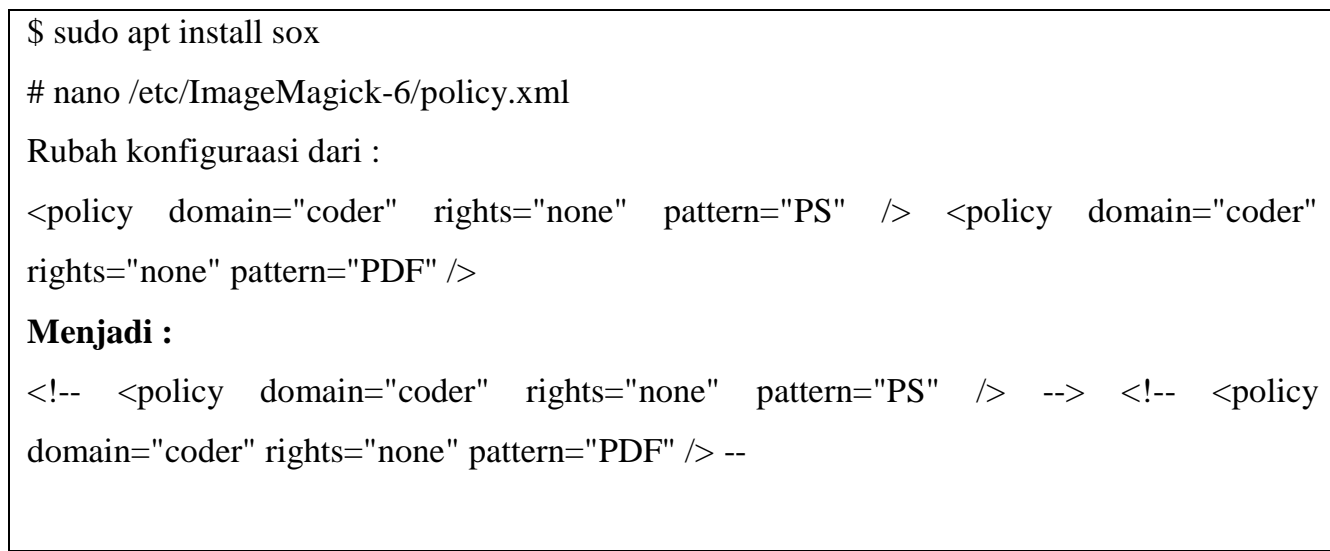

Pada tahap ini setelah terkonfigurasi dengan baik dan selesai dilakukan langkah selanjutnya adalah menganalisa pengaruh variasi client terhadap privat cloud dengan layanan video conference setiap parameter Qos.

\section{HASIL DAN PEMBAHASAN}

Bagian ini akan menjabarkan mengenai hasil dan pembahasan penelitian yang dilakukan yaitu hasil perbandingan harga dan analisa hasil eksperimen.

\subsection{Perbandingan Harga}

a. Komponen Fisik

Pada penelitian ini membangun layanan video conference dengan menggunakan aplikasi openmeetings yang memiliki hardware Requirements sebesar $2 \mathrm{GHz}$ untuk kecepatan CPU dan 4 GB untuk kapasitas RAM. Pada Tabel 5 terdapat harga komponen fisik berdasarkan referensi web online penjualan www.enterkomputer.com yang diperlukan untuk membangun server openmeetings.

Tabel 4 Biaya komponen fisik

\begin{tabular}{ccc}
\hline Komponen & Spesifikasi & Harga (IDR) \\
\hline CPU & 2 Core 3.3Ghz (LGA 1151) & 1.310 .000 \\
RAM & 4GB DDR4 & 440 \\
Harddisk & WDC 80GB & 85 \\
Motherboard & Support LGA1151, DDR4 & 1.390 .000 \\
& Total & $\mathbf{3 . 2 2 5 . 0 0 0}$ \\
\hline
\end{tabular}

\section{b. Komponen Cloud}

Saat menerapkan konsep dari Cloud untuk membangun server openmeetings secara virtual di dalam cloud karena dapat mengurangi biaya peralatan dan mengurangi konsumsi daya [17]. Biaya untuk membangun konsep server cloud dari penyedia layanan NEOCloud untuk menjalankan layanan video conference dengan menggunakan software openmeetings dapat dilihat pada tabel 6.

Tabel 5 Biaya komponen logic (cloud) 


\begin{tabular}{ccc}
\hline Komponen & Spesifikasi & Harga (IDR) / Bulan \\
\hline \multirow{2}{*}{ Virtual Compute } & CPU 2 Core & \\
& 2 GB RAM & 330.000 \\
Flex Storage & 60 GB Boot Storage & \\
& 20 GB & 26.500 \\
& Total & $\mathbf{3 5 6 . 5 0 0}$ \\
\hline
\end{tabular}

\section{c. Hasil Perbandingan Harga}

Dari perbandingan antara biaya yang digunakan untuk membangun sebuah Server Openmeetings, biaya Cloud lebih murah yaitu sebesar Rp 356.000 untuk jangka waktu 30 Hari atau Rp 12.000 per hari dibandungkan dengan biaya komponen secara fisik sebesar Rp 3.225.000. Selain biaya yang lebih efisien, pengguna Cloud mendapatkan kemudahan dalam mengakses Server atau data, untuk mengakses yang diperlukan tidak perlu berada pada suatu komputer yang sama karena Server atau data dapat diakses di mana saja dan kapan saja.

\subsection{Hasil Pengujian}

Hasil rata-rata parameter QoS throughput, delay, jitter dan packet loss diambil dari hasil konferensi menggunaan skenario jumlah pengguna yang berbeda yaitu 3 client, 5 client, 7 client dan 9 client berdurasi 1 dan 5 menit. Nilai rata-rata dari parameter QoS pada layanan video conference merupakan capture hasil dari Real Time Messaging Protocol (RTMP). Kriteria hasil percobaan video conference pada cloud pada sisi PC client ke server seperti yang ditunjukkan pada Tabel 7.

Tabel 6 Hasil Pengujian

\begin{tabular}{|c|c|c|c|c|c|}
\hline Val & abel & Durasi & Delay & Packet Loss & Jitter \\
\hline \multirow{4}{*}{3 Client } & \multirow{2}{*}{ Upload } & 1 Menit & Sangat Baik & Sangat Baik & Sangat Baik \\
\hline & & 5 Menit & Sangat Baik & Sangat Baik & Sangat Baik \\
\hline & \multirow{2}{*}{ Download } & 1 Menit & Sangat Baik & Sangat Baik & Sangat Baik \\
\hline & & 5 Menit & Sangat Baik & Sangat Baik & Sangat Baik \\
\hline \multirow{4}{*}{5 Client } & \multirow{2}{*}{ Upload } & 1 Menit & Sangat Baik & Sangat Baik & Sangat Baik \\
\hline & & 5 Menit & Sangat Baik & Sangat Baik & Sangat Baik \\
\hline & \multirow{2}{*}{ Download } & 1 Menit & Sangat Baik & Sangat Baik & Sangat Baik \\
\hline & & 5 Menit & Sangat Baik & Sangat Baik & Sangat Baik \\
\hline \multirow{4}{*}{7 Client } & \multirow{2}{*}{ Upload } & 1 Menit & Sangat Baik & Sangat Baik & Sangat Baik \\
\hline & & 5 Menit & Sangat Baik & Sangat Baik & Sangat Baik \\
\hline & \multirow{2}{*}{ Download } & 1 Menit & Sangat Baik & Sangat Baik & Sangat Baik \\
\hline & & 5 Menit & Sangat Baik & Sangat Baik & Sangat Baik \\
\hline \multirow{4}{*}{7 Client } & \multirow{2}{*}{ Upload } & 1 Menit & Sangat Baik & Sangat Baik & Sangat Baik \\
\hline & & 5 Menit & Sangat Baik & Sangat Baik & Sangat Baik \\
\hline & \multirow{2}{*}{ Download } & 1 Menit & Sangat Baik & Sangat Baik & Sangat Baik \\
\hline & & 5 Menit & Sangat Baik & Sangat Baik & Sangat Baik \\
\hline
\end{tabular}

Hasil pengujian eksperimen yang didapatkan dari sisi upload dan download paramter delay untuk durasi 1 menit dan 5 menit termasuk dalam kategori sangat baik dengan nilai terbesar yang dihasilkan adalah $20.22 \mathrm{~ms}$ dimana batas ambangnya $150 \mathrm{~ms}$, sehingga menunjukkan bahwa proses komunikasi untuk layanan video conference pada cloud dapat berjalan baik. Senada dengan parameter jitter yang didapatkan untuk durasi 1 menit dan 5 termasuk dalam kategori sangat baik dengan nilai terbesar yang dihasilkan adalah $10.35 \mathrm{~ms}$ dimana batasan nilai sangat baik yaitu bernilai kurang dari $75 \mathrm{~ms}$. Kemudian Packet Loss dari hasil yang didapatkan untuk durasi 1 menit dan 5 menit termasuk dalam kategori sangat baik dengan nilai terbesar yang dihasilkan adalah $0.94 \%$ sangat baik artinya yang bernilai kurang dari $2 \%$. 


\section{KESIMPULAN}

Di Era pandemi ini, membangun infrastruksur cloud berbasis platform openstack untuk layanan video conference mampu mengurangi biaya operasional dan investasi komunikasi jaringan. Hal ini ditunjukan dengan perbandingan harga komponen cloud lebih ekonomis. Selain itu, merujuk pada kinerja kualitas dari layanan cloud yang dibangun dalam penelitian ini dengan menggunakan konferensi video termasuk dalam parameter sangat baik, sehingga layak diimplementasikan.

\section{UCAPAN TERIMAKASIH}

Penulis mengucapkan terima kasih kepada semua pihak yang telah membantu penulisan penelitian ini.

\section{DAFTAR PUSTAKA}

[1] M. D. D. M. a. S. H. D. M. F. Robert T. Cristel, "Video Conferencing Impact on Facial Appearance: Looking Beyond the COVID-19 Pandemic," Facial Plastic Surgery \& Aesthetic Medicine, vol. 22, no. 4, p. 238, 2020.

[2] APJII, "Penetrasi \& Perilaku Pengguna Internet Indonesia," Hasil Survey 2017, 31 Agustus 2018.

[3] N. Afif, "IMPLEMENTASI OPEN MEETINGS MENGGUNAKAN RASPBERRY PI," Jurnal INSTEK (Informatika Sains dan Teknologi), vol. 2, no. 2, p. 31, 2017.

[4] R. T. B. G. A. S. a. A. K. Tamas Pflanzner, "Performance Analysis of an OpenStack Private Cloud," in Proceedings of the 6th International Conference on Cloud Computing and Services Science (CLOSER 2016) , 2016.

[5] A. Budiyanto, Pengantar Cloud Computing, CloudIndonesiA.ORG, 2012.

[6] M. He, A. M. Alba, E. Mansour and W. Kellerer, "Evaluating the Control and Management Traffic in OpenStack Cloud with SDN," in 2019 IEEE 20th International Conference on High Performance Switching and Routing (HPSR), 2019.

[7] M. I. Y. N. S. N. a. K. S. Yoji Yamato, "Fast and Reliable Restoration Methodof Virtual Resources on OpenStack," IEEE TRANSACTIONS ON CLOUD COMPUTING, vol. 6, no. 2, p. 572, 2018.

[8] A. Vogel, D. Griebler, C. A. F. Maron, C. Schepke and L. G. Fernandes, "Private IaaS Clouds: A Comparative Analysis of OpenNebula, CloudStack and OpenStack," in 2016 24th Euromicro International Conference on Parallel, Distributed, and Network-Based Processing (PDP), 2016.

[9] A. F. F. E. M. A. Muhammad Fauzan, "ANALISIS DAN PERANCANGAN INFRASTRUKTUR PRIVATE CLOUD DENGAN OPENSTACK," Jurnal Pseudocode,, vol. iv, no. 2, pp. 180-189, 2017.

[10] M. Ananth and R. Sharma, "Cost and Performance Analysis of Network Function Virtualization Based Cloud Systems," in 2017 IEEE 7th International Advance Computing Conference (IACC), 2017.

[11] S. F. W. H. Hafis Nurdin, "Clustering OpenmeetingsGuna Peningkatan Efektivitas Belajar Mengajar Jarak Jauh," JIMP -Jurnal Informatika Merdeka Pasuruan, vol. 3, no. 2, p. 39, 2018.

[12] B. A. Forouzan, Data Communications and Networking, Huga Media, 2007.

[13] G. Utama, Berfikir Objek: Cara Efektif Menguasai Java, IlmuKomputer.Com, 2002 .

[14] "Adobe Flash Player," [Online]. Available: https://get.adobe.com/flashplayer/about/. [Accessed 10 maret 2020].

[15] "About MariaDB," [Online]. Available: https://mariadb.org/about/. [Accessed 10 maret 2020].

[16] "red5.org," [Online]. Available: http://red5.org/. [Accessed 15 maret 2020].

[17] ETSI, "portal.etsi.org," 22 October 2012. [Online]. Available: https://portal.etsi.org/NFV/NFV_White_Paper.pdf. 
